\title{
Pressure-induced collagen degradation in arterial tissue as a potential mechanism for degenerative arterial disease progression
}

\author{
Citation for published version (APA): \\ Gaul, R. T., Nolan, D. R., Ristori, T., Bouten, C. V. C., Loerakker, S., \& Lally, C. (2020). Pressure-induced \\ collagen degradation in arterial tissue as a potential mechanism for degenerative arterial disease progression. \\ Journal of the Mechanical Behavior of Biomedical Materials, 109, [103771]. \\ https://doi.org/10.1016/j.jmbbm.2020.103771
}

\section{Document license: \\ TAVERNE}

DOI:

10.1016/j.jmbbm.2020.103771

Document status and date:

Published: 01/09/2020

\section{Document Version:}

Publisher's PDF, also known as Version of Record (includes final page, issue and volume numbers)

\section{Please check the document version of this publication:}

- A submitted manuscript is the version of the article upon submission and before peer-review. There can be important differences between the submitted version and the official published version of record. People interested in the research are advised to contact the author for the final version of the publication, or visit the DOI to the publisher's website.

- The final author version and the galley proof are versions of the publication after peer review.

- The final published version features the final layout of the paper including the volume, issue and page numbers.

Link to publication

\footnotetext{
General rights

- You may freely distribute the URL identifying the publication in the public portal. follow below link for the End User Agreement:

www.tue.nl/taverne

\section{Take down policy}

If you believe that this document breaches copyright please contact us at:

openaccess@tue.nl

providing details and we will investigate your claim.
}

Copyright and moral rights for the publications made accessible in the public portal are retained by the authors and/or other copyright owners and it is a condition of accessing publications that users recognise and abide by the legal requirements associated with these rights.

- Users may download and print one copy of any publication from the public portal for the purpose of private study or research.

- You may not further distribute the material or use it for any profit-making activity or commercial gain

If the publication is distributed under the terms of Article $25 \mathrm{fa}$ of the Dutch Copyright Act, indicated by the "Taverne" license above, please 


\title{
Pressure-induced collagen degradation in arterial tissue as a potential mechanism for degenerative arterial disease progression
}

\author{
Robert T. Gaul $^{\mathrm{a}, \mathrm{b}}$, David R. Nolan ${ }^{\mathrm{a}, \mathrm{b}}$, Tommaso Ristori ${ }^{\mathrm{c}, \mathrm{d}}$, Carlijn V.C. Bouten ${ }^{\mathrm{c}, \mathrm{d}}$, \\ Sandra Loerakker ${ }^{\mathrm{c}, \mathrm{d}}$, Caitríona Lally ${ }^{\mathrm{a}, \mathrm{b}, \mathrm{e}, *}$ \\ a Trinity Centre for Biomedical Engineering, Trinity College Dublin, Dublin, Ireland \\ ${ }^{\mathrm{b}}$ School of Engineering, Trinity College Dublin, Dublin, Ireland \\ ${ }^{\mathrm{c}}$ Department of Biomedical Engineering, Eindhoven University of Technology, the Netherlands \\ ${ }^{\mathrm{d}}$ Institute for Complex Molecular Systems, Eindhoven University of Technology, the Netherlands \\ ${ }^{\mathrm{e}}$ Advanced Materials and Bioengineering Research Centre (AMBER), Royal College of Surgeons in Ireland and Trinity College Dublin, Dublin, Ireland
}

\section{A R T I C L E I N F O}

\section{Keywords:}

Artery

Collagen

Degradation

Strain-dependent

Pressure-induced

\begin{abstract}
A B S T R A C T
Collagen fibre degradation is a strain-dependent process, whereby the magnitude of experienced strain dictates the rate of enzymatic cleavage. Studies have identified conflicting findings as to whether strain inhibits or enhances collagen degradation, which may be explained by the tissue type and tissue scale investigated, as well as the strain range considered. The aim of this study is to identify, for the first time, the strain-dependent degradation response of intact arterial vessels experiencing physiological pressures and apply these findings to a computational model to better understand degenerative arterial diseases, such as aneurysms.

To achieve this, a series of quasi-static pressure inflation experiments were carried out on intact arteries in the presence of purified bacterial collagenase at physiologically relevant pressures to investigate collagen matrix degradation in the vascular wall. A complementary computational model was developed to explore the complex role of pressure, non-collagenous matrix contribution, and collagen fibre crimp in the ultimate degradation response of the vessel.

Pressure induced inflation-degradation results identified an increased rate of vessel expansion and reduced time to failure with increasing pressure in the vessels. Interestingly, our computational model was able to capture this same response, including the elevated rates of degradation which occur at low pressures. These findings highlight the critical role of strain in collagen degradation, particularly in cases of arterial disease, such as aneurysm formation, whereby structural integrity may be compromised.
\end{abstract}

\section{Introduction}

Collagen fibre remodelling, consisting of reorientation, production and degradation of collagen is central to healthy and diseased arterial remodelling. Collagen degradation, in particular, is critical in dictating the mechanical stability of collagenous tissues, with excessive degradation linked to atherosclerotic plaque cap rupture (Aikawa, 2004; Daemen et al., 2016) as well as aneurysm progression and rupture (Thompson et al., 2002). Collagen fibre degradation has also been identified as a strain-dependent process where strain has been found to enhance (Ellsmere et al., 1999; Willett et al., 2008) as well as inhibit (Lotz et al., 2008; Nabeshima et al., 1996; Robitaille et al., 2011; Ruberti and Hallab, 2005; Wyatt et al., 2009; Zareian et al., 2010) collagen degradation. A greater understanding of this strain-driven remodelling response may provide fundamental insights into arterial disease progression and the biomechanical responses following medical device deployment.

Our previous work (Gaul et al., 2018) uncovered an underlying V-shaped degradation response in arterial collagen, where strain initially reduces the degradation rate before once again increasing above a strain protective threshold. This response was partially masked at the tissue scale by the mechanical contribution of non-collagenous matrix and a transmural gradient of collagen fibre crimp. A complementary 1D numerical model supported this finding, highlighting the importance of this non-collagenous matrix and crimp gradient in the ultimate degradation response observed at the tissue scale. However, these findings

\footnotetext{
* Corresponding author. Trinity Centre for Biomedical Engineering, Trinity Biomedical Sciences Institute, Trinity College Dublin, Dublin, Ireland.

E-mail address: lallyca@tcd.ie (C. Lally).
} 
were determined in excised dogbone specimens, which have an altered gradient of collagen fibre crimp and altered residual stresses compared to physiologically relevant native vessel geometries (Gaul et al., 2018; Holzapfel et al., 2007). These structural changes may affect the degradation response observed experimentally in vitro. Understanding the physiologically relevant tissue scale response of intact vessels is therefore critical in understanding and treating diseases which, if left unchecked, may lead to an adverse clinical event (Thompson et al., 2002).

A number of studies have identified a similar V-shaped collagen degradation profile in response to applied strain (Ghazanfari et al., 2016a; Huang and Yannas, 1977; Yi et al., 2016). Interestingly, the strain at which a minimum degradation response occurs was found to be significantly different depending on the tissue scale investigated. Studies on reconstituted collagen tapes identified a collagen protection mechanism at approximately $3.5 \%$ strain (Huang and Yannas, 1977) in contrast to approximately $20 \%$ strain in bovine pericardium (Ghazanfari et al., 2016a), lung tissue (Yi et al., 2016) and artery (Gaul et al., 2018). It has been suggested that this degradation response may be influenced by moving from the nanoscale to the macroscale due to molecular, fibril and fibre sliding, unfolding, reorientation and straightening (Chang et al., 2012; Chang and Buehler, 2014; Gaul et al., 2018; Willett et al., 2008). Similarly, packing of collagen molecules into fibrils and fibres may influence the degradation response further by increasing the structural stability of the collagen (Miles and Ghelashvili, 1999; Willett et al., 2008).

A number of computational models have been developed in order to more thoroughly investigate the collagen degradation response observed experimentally (Gaul et al., 2018; Heck et al., 2015; Loerakker et al., 2014; Tonge et al., 2015) as well as predict disease development and progression (Grytz et al., 2012; Loerakker et al., 2016). Using an energy-based approach, Tonge et al. were able to capture the degradation response of bovine pericardium (Ellsmere et al., 1999) and corneal tissue (Zareian et al., 2010) observed experimentally through a reduction in collagen fibre radius (Tonge et al., 2015). Using a strain-based approach resulting in a collagen volume change, Loerakker et al. were also able to predict the remodelling response of tissue engineered heart valves in vivo, showing increased likelihood of valvular insufficiency when valves are implanted in the low pressure pulmonary position in comparison to the aortic valve position (Loerakker et al., 2016). Degradation models have also been used to predict thickening of lamina cribrosa, a connective tissue structure supporting axons exiting the eye, which occurs in early glaucoma and has been associated with maladaptive remodelling (Grytz et al., 2012). Similar degradation models may help elucidate maladaptive remodelling of collagen in arterial diseases, which may ultimately be responsible for plaque and aneurysm weakening and rupture (Aikawa, 2004; Bersi et al., 2019; Daemen et al., 2016; Thompson et al., 2002). However, before inferring conclusions from computational simulations of arterial diseases, it is important to confirm that our previous findings describing collagen degradation for excised arterial dogbone specimens (Gaul et al., 2018) are also applicable in the case of intact vessels, under physiological pressures and with residual stresses.

Therefore, the aim of this study is to determine the strain-dependent degradation response of collagen in intact arterial vessels at physiologically relevant blood pressures and to show a case study exhibiting how these experimental findings can be adopted to inform computational models for arterial disease. To achieve this, the study had the following specific aims; 1) to propose and employ an experimental method to investigate the creep response of intact vessels as they degrade in the presence of collagenase at constant pressures, and 2) to develop a 3D finite element model based on our findings and our previous study (Gaul et al., 2018), to explain our experimental creep data.

\section{Methods}

\subsection{Tissue preparation}

Fresh porcine common carotid arteries were excised from 6-monthold Large White pigs $(\mathrm{n}=30$ ) weighing approximately $80 \mathrm{~kg}$ at the time of slaughter. Excised carotid arteries were taken from the proximal end of the vessel (Trabelsi et al., 2019) and then frozen to $-80^{\circ} \mathrm{C}$ at a controlled rate of $-1{ }^{\circ} \mathrm{C} / \mathrm{min}$ in a cryoprotectant media to maintain mechanical and structural properties during storage (Müller-Schweinitzer, 2009). Prior to testing, vessels were thawed in a water bath at 37 ${ }^{\circ} \mathrm{C}$ to minimise tissue damage (Pegg et al., 1997), washed in PBS to remove any residual cryoprotectant and cut to approximately $30 \mathrm{~mm}$ in length for testing. Loose connective tissue was carefully removed using a forceps and scalpel. This served a dual purpose: it facilitated the easy application of a speckle pattern for accurate surface strain measurement, and produced a more uniform specimen geometry for structural analysis. Each specimen was then cannulated using nylon barbs and tied using nylon thread. A speckle pattern, which is required for digital image correlation (DIC) strain analysis, was then applied using black alkyd resin spray paint from a distance of approximately $70 \mathrm{~cm}$. Unlike ink dots, that are often applied directly to tissue for strain tracking, which can dehydrate the tissue, spray paint ink effectively dries as it lands on the tissue, minimising potential tissue dehydration which may influence mechanical results. In order to mitigate the risk of pattern disruption during testing, the following procedure was performed: 1) sample was blotted dry, 2) speckle pattern was applied, 3) loose paint flakes were blotted off with tissue, 4) sample was placed in PBS to wash off any other loose paint flakes, 5) sample was blotted one final time to remove any remaining loose flakes before testing.

\subsection{Pressure inflation experiments}

\subsubsection{Pressure inflation setup}

To assess the structural response of intact vessels to collagen degradation, pressure inflation tests were carried out in the presence of purified bacterial collagenase. To achieve this, one end of the cannulated vessel was connected to a Proportional Integral Derivative (PID) controlled syringe pump and the other end was sealed with a cap, allowing for free axial expansion under inflation (Fig. 1). A pressure transducer was then inserted through a valve fitting enabling a constant pressure to be maintained as the vessel degrades. Once connected, the vessel was placed in a PID temperature-controlled water bath at $37^{\circ} \mathrm{C}$. The pressure feedback system was controlled via LabVIEW (National Instruments, Berkshire, UK). To reduce the system complexity and allow meaningful conclusions on the strain-dependent collagen degradation mechanism in arteries to be determined, no axial strain was applied to the vessel, although axial tethering is known to be present in vivo. This condition was applied to ensure that circumferential strain remains the principal strain direction, even at low pressures, and to ensure that collagen fibres remain predominantly orientated in the circumferential direction throughout the experiments.

\subsubsection{Strain measurement}

Strain was tracked throughout degradation using a commercially available stereo camera Digital Image Correlation (DIC) system (Dantec Dynamics, Ulm, Germany), allowing for 3D strain mapping (Fig. 2). Prior to testing, the system was calibrated in a water bath to mimic testing conditions. Calibration was performed using a checkerboard plate of known dimensions supplied by Dantec Dynamics. The plate was tilted in all planes with 8-10 images being acquired through the DIC cameras. This allows the software to determine the angle between the cameras and the distance to the sample. The checkerboard calibration was carried out in solution at the location of sample testing to ensure the diffraction of light caused by the solution was accounted for.

After specimen testing, circumferential strain data was determined 


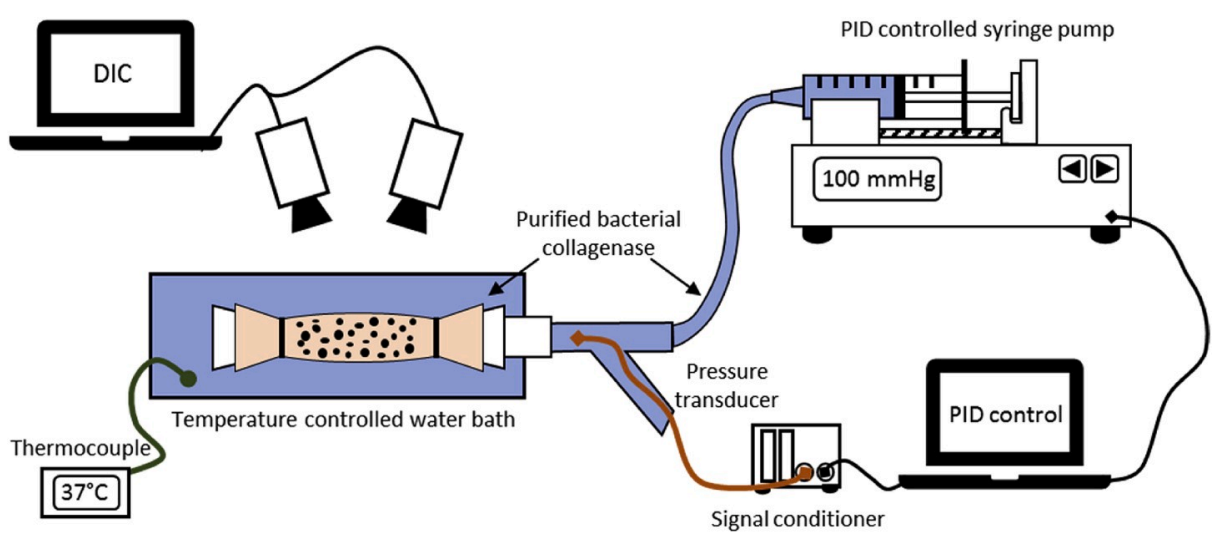

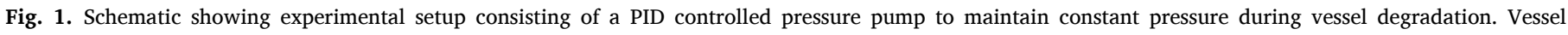

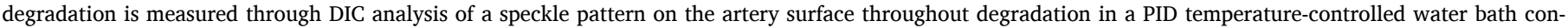
taining purified bacterial collagenase.

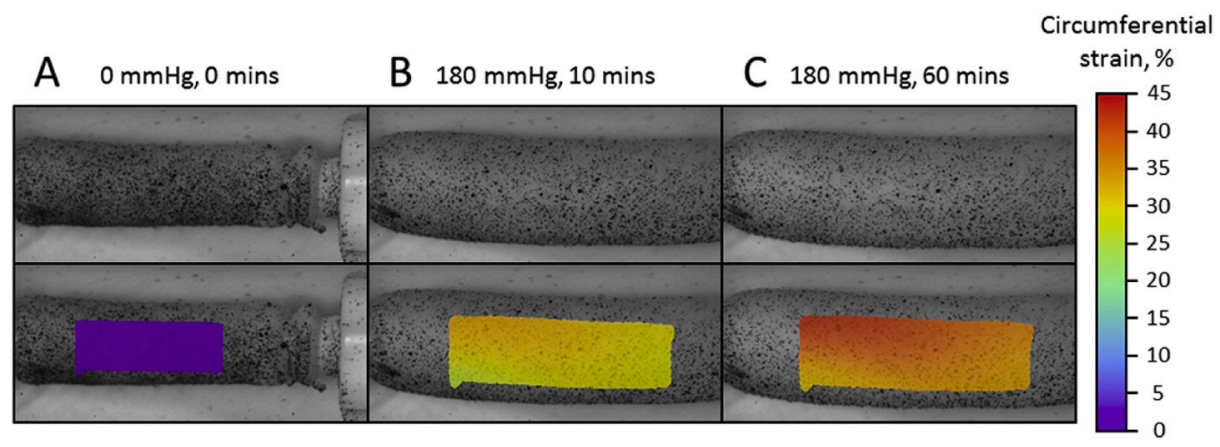

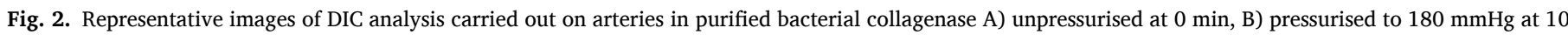
min and C) pressurised to $180 \mathrm{mmHg}$ at $60 \mathrm{~min}$. Top panel shows raw images, bottom panel shows circumferential strain overlaid.

across the central portion of the vessel as shown in Fig. 2. Vessel edges were not included in the analysis due to the increased likelihood of edge effects influencing measurements, and the increased likelihood of these areas being out of focus as the furthest regions from the cameras.

The resulting strains were exported and post-processed in Matlab (MathWorks, Cambridge, UK) to determine the mean change in diameter in the circumferential direction as the vessel degrades at a given pressure. Strain measurements acquired using the DIC system were compared to a subset of diameter measurements, determined using ImageJ, for system validation (Schneider et al., 2012). Although DIC provides a full non-homogenous strain field across the vessel wall, the mean circumferential strain across the vessel surface was calculated in order to compare the degradation response at different pressures. Wall thickness of all vessels was determined by taking a ring section from the ends of each vessel and using a measuring microscope with a micrometer stage.

\subsubsection{Pressure expansion tests}

Once set up, purified bacterial collagenase $(400 \mathrm{U} / \mathrm{ml}$; Worthington Biochemical, USA) in PBS supplemented with calcium and magnesium (D8662; Sigma-Aldrich, Ireland) was added to both the syringe and the water bath. Each specimen was then pressurised to a fixed, constant pressure until either vessel rupture or the entire collagenase filled syringe volume $(16 \mathrm{ml})$ permeated through the vessel wall and the syringe emptied. Each vessel was subjected to just one pressure. Different vessels were pressurised from $60 \mathrm{mmHg}$ to $180 \mathrm{mmHg}$ in $40 \mathrm{mmHg}$ increments to determine vessel degradation across a large physiological pressure range. The experimental setup is depicted in Fig. 1. Three specimens were tested at each fixed pressure in the presence of collagenase, while one control vessel was evaluated at each pressure in the absence of collagenase. Additionally, separate pressure-diameter curves were determined across 5 vessels for model calibration. The current setup did not allow the separation of expansion due to degradation and that due to the viscoelasticity of the arterial tissue. This was due to time constraints which did not permit the application of the speckle pattern after preconditioning of the vessel to remove viscous effects, i.e. it would take too long to apply the speckle pattern that the viscous affects would no longer be removed and the sample would have to be preconditioned again. By evaluating the timescale at which viscous creep was observed to occur in control vessels (approximately $90 \%$ of final recorded value at $10 \mathrm{~min}$ ), however, it was clear that it was not necessary to separate these effects when evaluating pressure-induced degradation trends in arterial tissue, as degradation occurs at a considerably longer timescale than the viscous effects.

\subsubsection{Investigation of low pressure degradation}

To comprehensively investigate the degradation response at low pressures, that is, where minimal diameter changes occur, an additional set of pressure inflation experiments were carried out in a similar fashion to those outlined in Section 2.2.3. The objective of these experiments was to determine whether there is a higher rate of collagen degradation at low pressures, thus investigating the low strain region of the V-shaped degradation profile. Vessels were first pressurised in purified bacterial collagenase to either $60 \mathrm{mmHg}$ or $100 \mathrm{mmHg}$ for $45 \mathrm{~min}$ to allow for collagen degradation to occur. Vessel pressure was then removed before a pressure of $180 \mathrm{mmHg}$ was reapplied while minimising any downtime. The time to failure was recorded and was used as a measure of how much collagen degradation had occurred at low pressure. The shorter the time to failure, the more the collagen that had been degraded at a specific pressure in the initial 45-min period. 


\subsection{Histological processing}

Degraded vessel sections and undegraded adjacent sections of vessels were processed for histology to confirm collagen degradation. All samples were fixed in $10 \%$ formalin overnight at $4{ }^{\circ} \mathrm{C}$, dehydrated in a graded series of ethanol baths (EtOH), cleared in xylene before being embedded in paraffin wax. The resulting paraffin-embedded samples were sectioned into $8 \mu \mathrm{m}$ slices using a microtome (RM-2125RT, LEICA, Germany) and affixed to microscope slides. Slides were stained with picrosirius red and viewed under polarised light to evaluate collagen degradation. Picrosirius red enhances the natural birefringence of collagen allowing one to only see collagen when viewed under polarised light (Fig. 3) (Junqueira et al., 1979). The absence of collagen is clearly visible under polarised light by the absence of birefringence (appears as a completely black image when all collagen is absent).

\subsection{Model development}

To model vessel degradation under constant pressure, we modified a 1D constitutive law used to model collagen degradation in layered soft tissues (Gaul et al., 2018) for use in 3D finite element simulations. The constitutive law comprises an anisotropic collagen fibre component and an isotropic non-collagenous matrix component accounting for constituents such as elastin, glycosaminoglycans and the passive response of smooth muscle cells. Although elastin fibre directionality has been observed, it is far less aligned than that of collagen while also being less mechanically significant (Krasny et al., 2017). A more thorough description of the model can be found elsewhere (Gaul et al., 2018). The total Cauchy stress, $\sigma_{t}$, at a material point is given by:

$\boldsymbol{\sigma}_{t}=\boldsymbol{\sigma}_{f}+\boldsymbol{\sigma}_{m}$

where $\sigma_{f}$ and $\sigma_{m}$ are the fibre and matrix stress tensors respectively.

Collagen fibre crimp, which can be seen experimentally in unpressurised arteries (see Fig. 3), is modelled by using a multiplicative split of the total stretch, $\lambda_{t}$, into the stretch of a collagen fibre, $\lambda_{f}$, and a precrimp component, $\lambda_{p}$.

$\lambda_{t}=\lambda_{f} \lambda_{p}$.

Precrimp, $\lambda_{p}$, quantifies the degree of crimp or pretension experienced by a collagen fibre and is a prescribed constant at the beginning of the simulation and does not change as load is applied. To set collagen fibres to be crimped in the initial configuration one must prescribe a $\lambda_{p}>$ 1 , such that a $\lambda_{f}<1$ emerges. Likewise, if $\lambda_{p}<1$ is prescribed, collagen fibres begin in tension in the initial configuration. Importantly, collagen fibres are assumed to only bear load in tension, and thus, do not contribute to the stress until a $\lambda_{f}>1$.

Unlike our previous degradation model (Gaul et al., 2018), and more similar to (Loerakker et al., 2014), collagen fibres have an exponential stress-stretch relationship as proposed by Driessen et al. (2007) which is scaled by the collagen volume fraction: $\boldsymbol{\sigma}_{f}=\left\{\begin{array}{cc}\varphi_{f} k_{1}\left(\lambda_{f}\right)^{2}\left(e^{k_{2}\left(\left(\lambda_{f}\right)^{2}-1\right)}-1\right)[\boldsymbol{a} \otimes \boldsymbol{a}] & \lambda_{f} \geq 1 \\ 0 & \lambda_{f}<1\end{array}\right.$

where $\varphi_{f}$ is the collagen volume fraction, $k_{1}$ and $k_{2}$ are collagen fibre stiffness parameters calibrated to experimental data, $\lambda_{f}$ is the collagen fibre stretch for a given collagen crimp, $\lambda_{p}$, and tissue stretch, $\lambda_{t}$, defined in Equation (2) and $\boldsymbol{a}$ is a vector representing the fibre direction in the deformed configuration and the operator $\boldsymbol{a} \otimes \boldsymbol{a}=\boldsymbol{a} \boldsymbol{a}^{T}$. In this study we use a single family of circumferential collagen fibres, as observed in the porcine carotid artery (Gaul et al., 2017; Sáez et al., 2016; Shahid et al., 2017), unlike other vessels (Schriefl et al., 2012).

The non-collagenous matrix contribution to the total stress was modelled using a Neo-Hookean material [Loerakker et al., 2014] and scaled by its volume fraction:

$\boldsymbol{\sigma}_{m}=\varphi_{m}\left(\kappa \frac{\ln (J)}{J} \boldsymbol{I}+\frac{G}{J}\left(\boldsymbol{B}-J^{2 / 3} \boldsymbol{I}\right)\right)$

where $\varphi_{m}$ is the non-collagenous matrix volume fraction, $J=\operatorname{det}(\boldsymbol{F})$, $\boldsymbol{B}=\boldsymbol{F} \cdot \boldsymbol{F}^{T}, \boldsymbol{F}$ is the deformation gradient tensor, and $\kappa$ and $G$ are the bulk and shear modulus, respectively. The contribution of fibre and matrix stress which are weighted by their volume fractions, $\varphi_{f}$ and $\varphi_{m}$, respectively, sum to unity.

\subsubsection{Stress degradation}

Collagen degradation was modelled by reducing the collagen volume fraction over time based on the collagen fibre stretch using a first order rate equation,

$\frac{d \varphi_{f}}{d t}=-\Psi_{f} \varphi_{f}$

where $\Psi_{f}$ is the degradation rate constant function.

As the collagen volume fraction reduces, so too does the collagen stress contribution as outlined in Equation (3). Collagen degradation was described by a V-shaped degradation profile based on our own findings (Gaul et al., 2018) and findings in literature (Ghazanfari et al., 2016a; Huang and Yannas, 1977; Yi et al., 2016), where stretch initially reduces the degradation rate before degradation once again increases above a protective stretch threshold (Fig. 4). This V-shaped profile was captured using a smoothed bilinear function with three domains; low strain, transition strain, and high strain (O'Connor et al., 2017). The low and high linear domains are connected using a quadratic function in the transition domain. Consequently, the collagen fibre degradation rate, $\Psi_{f}$, is described by the continuous stepwise function,

$\Psi_{f}=D_{c}+ \begin{cases}D_{l} \varepsilon_{f}, & \varepsilon_{f}<\varepsilon_{t 1}^{D} \\ T_{1}^{D} \varepsilon_{f}^{2}+T_{2}^{D} \varepsilon_{f}+T_{3}^{D}, & \varepsilon_{t 1}^{D} \leq \varepsilon_{f} \leq \varepsilon_{t 2}^{D}, \\ D_{h}\left(\varepsilon_{f}-\varepsilon_{t 2}^{D}\right)+T_{1}^{D} \varepsilon_{t 2}^{D^{2}}+T_{2}^{D} \varepsilon_{t 2}^{D}+T_{3}^{D}, & \varepsilon_{f}>\varepsilon_{t 2}^{D}\end{cases}$

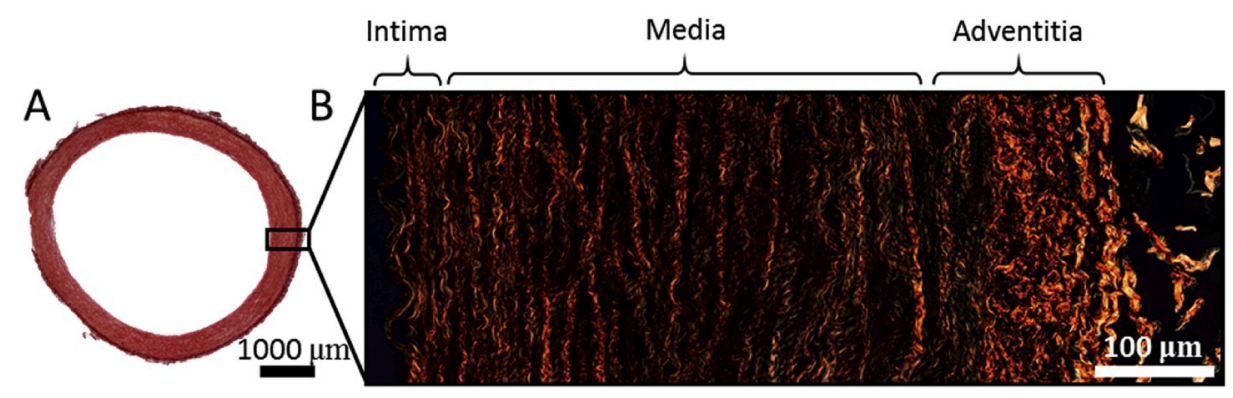

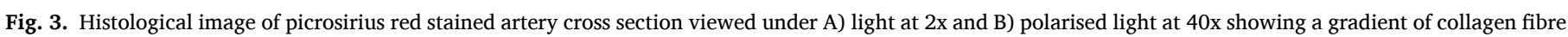

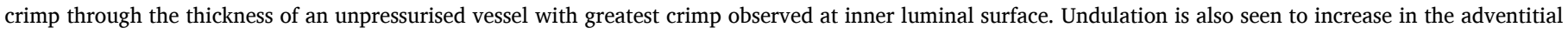
tissue layer. (For interpretation of the references to colour in this figure legend, the reader is referred to the Web version of this article.) 


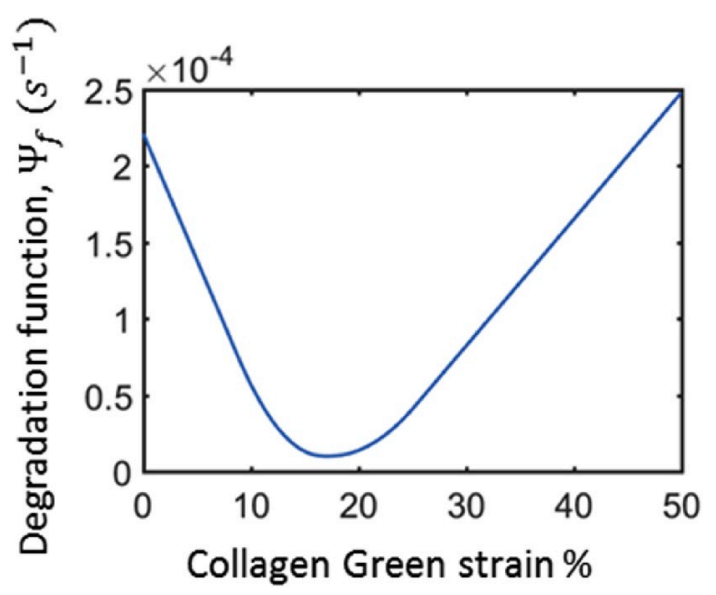

Fig. 4. Underlying V-shaped collagen degradation response, $\Psi_{f}$, for a single collagen fibre (Gaul et al., 2018). Degradation constants for given curve can be found in Table 1.

where $D_{l}$ and $D_{h}$ are the degradation moduli of the low strain and high strain regions respectively, the Green strain of the fibre, $\varepsilon_{f}=\left(\lambda_{f}^{2}-1\right) /$ $2 ; \varepsilon_{t 1}^{D}$ is the strain at which the low strain region switches to the transition region; $\varepsilon_{t 2}^{D}$ is the strain at which the transition region switches to the high strain region; and $D_{c}$ is a constant or baseline degradation rate which translates the bilinear curve along the $y$-axis. The parameters $T_{1}^{D}$, $T_{2}^{D}$, and $T_{3}^{D}$ ensure continuity between the three regions and are defined as,

$T_{1}^{D}=\left(D_{l}-D_{h}\right) /\left(2\left(\varepsilon_{t 1}^{D}-\varepsilon_{t 2}^{D}\right)\right)$

$T_{2}^{D}=D_{l}-\varepsilon_{t 1}^{D}\left(D_{l}-D_{h}\right) /\left(\varepsilon_{t 1}^{D}-\varepsilon_{t 2}^{D}\right)$.

$T_{3}^{D}=D_{l} \varepsilon_{t 1}^{D}-T_{1}^{D} \varepsilon_{t 1}^{D^{2}}-T_{2}^{D} \varepsilon_{t 1}^{D}$

To ensure conservation of mass, degraded collagen fibres are converted into a mechanically weak component using a reduction factor, $R$. As a result, Equation (4) is updated to account for this degraded material:

$\boldsymbol{\sigma}_{m}=\varphi_{m} \boldsymbol{\sigma}_{m}+R \boldsymbol{\sigma}_{f}\left(1-\varphi_{f}-\varphi_{m}\right)$

The second term on the right-hand side of Equation (8) accounts for the degraded material which no longer contributes to the stress in the tissue, with the expression in brackets (volume of degraded material) ensuring that the total volume fraction equals unity.

\subsubsection{Precrimp gradient}

The value of $\lambda_{p}$ is varied across the artery wall as a function of the radius $r$. To identify the idealised values of $\lambda_{p}$, we hypothesise that the gradient of collagen fibre crimp is minimised and the vessel strain is in a strain protection region at physiological pressure $(100 \mathrm{mmHg} / 13 \mathrm{kPa})$. In order to determine the average crimp gradient for an artery in the unpressurised state based on this hypothesis, the following process was carried out and is shown schematically in Fig. 5:

a) Assign an initial guess of the material parameters to an idealised vessel.

b) Apply a displacement boundary condition to achieve the circumferential engineering strain experienced experimentally in an untreated artery at $100 \mathrm{mmHg}$ at the outer diameter of the vessel (determined experimentally to be $20 \%$, see Fig. 6).

c) Iteratively optimise the maximum and minimum precrimp $\lambda_{p}$ across the wall thickness of the undeformed configuration such that, under the displacement boundary condition ( $100 \mathrm{mmHg}$ ), the value of $\lambda_{f}$ at every material point radially through the wall is approximately equal to 1.17 , which is the fibre stretch value that has been previously determined to have the lowest fibre degradation rate (Gaul et al., 2018). It is our assumption that, in a healthy vessel, collagen will be at this stretch configuration (Fig. 5A).

d) With the collagen precrimp $\lambda_{p}$ set, apply an internal pressure to the vessel lumen and calibrate the material properties $\left(E, k_{1}, k_{2}\right)$ from experimental pressure-strain measurements (Fig. 6) using the optimised precrimp distribution, $\lambda_{p}$ (Fig. 5B).

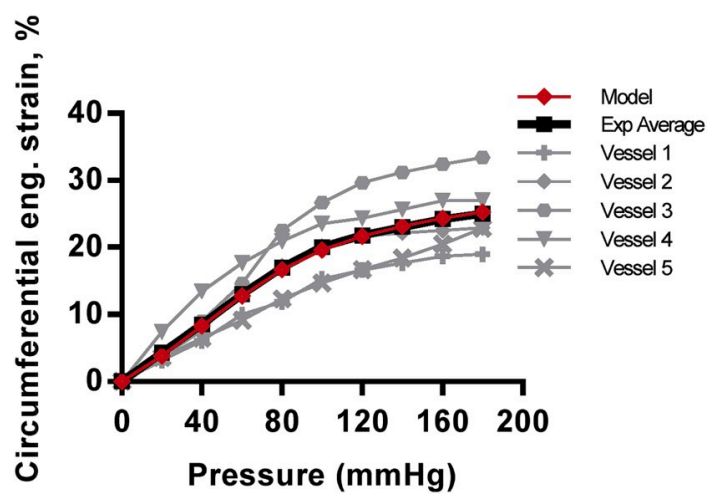

Fig. 6. Pressure-inflation curves for untreated porcine carotid arteries and the calibrated FE model. Individual vessels are shown in light grey with the average circumferential engineering strain for each pressure shown in black. The pressure-inflation response of the model is shown in red. (For interpretation of the references to colour in this figure legend, the reader is referred to the Web version of this article.)
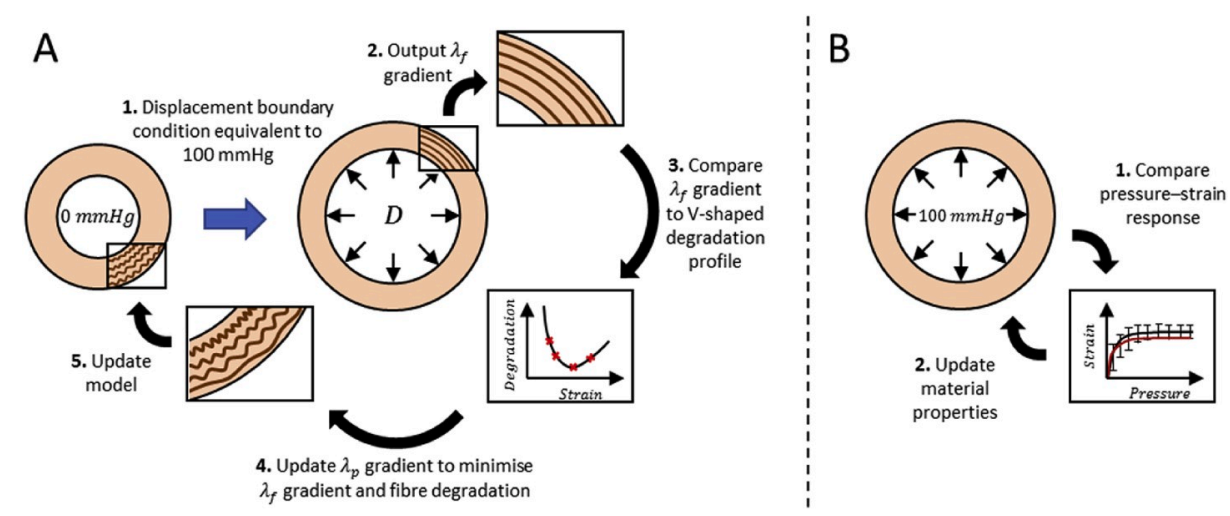

Fig. 5. Schematic showing A) calibration of the undeformed precrimp gradient only, by minimising the difference between the crimp occurring at a tissue strain equivalent to $100 \mathrm{mmHg}$ and the crimp at which collagen is protected from degradation (approximately 17\%). Once minimised, B) material properties are calibrated based on experimental pressure inflation curves. Calibration carried out in the absence of degradation. 


\subsubsection{Model calibration}

The values obtained for collagen and matrix volume fraction $\left(\varphi_{f}=\right.$ $\left.42 \%, \varphi_{m}=58 \%\right)$ were determined previously via image processing (Gaul et al., 2018) and are supported by literature (de Figueiredo Borges et al., 2008; Fischer and Llaurado, 1966; Tsamis et al., 2013). The gradient of precrimp, $\lambda_{p}$ across the wall is insensitive to the choice of initial material parameters due to the use of a displacement-controlled boundary condition. The material properties of the vessel wall were calibrated from experimentally measured pressure diameter curves shown in Fig. 6 after the gradient of fibre precrimp, $\lambda_{p}$ through the vessel wall was set (Section 2.4.2). Briefly, the Neo-Hookean non-collagenous matrix material stiffness, was calibrated from our experimental data at $60 \mathrm{mmHg}$ where minimal collagen was judged to be contributing to the load. This assumption was based on our experimental pressure degradation observations and histological evaluation of low pressure samples, where minimal vessel expansion was observed as collagen was degraded (Fig. 7 and Fig. 8). Once the values for $\lambda_{p}$ and the Neo-Hookean response were set, the anisotropic portion of our model was calibrated based on our experimental pressure-diameter curves by optimising $k_{1}$ and $k_{2}$, to reduce the error between our experimental and computational pressure-diameter curves, as shown in Fig. 6 . The parameters used in all simulations can be found in Table 1.

\subsection{In-silico pressure inflation - degradation tests}

To predict our pressure inflation-degradation experiments, we applied our degradation mechanics model to an idealised quarter finite element model of a cylindrical vessel geometry of similar dimensions to experimentally tested samples (inner radius $R_{i}=2 \mathrm{~mm}$, outer radius $R_{o}=3 \mathrm{~mm}$, length $l=0.5 \mathrm{~mm}$ ). Quadratic hexahedral hybrid elements with reduced integration were used to prevent element locking. Symmetry boundary conditions were applied to both circumferential side faces. The axial faces of the vessel were kept parallel using a constraint equation, mimicking the experimental setup described above and preventing convergence issues as the vessel degrades at different rates through its thickness. An internal luminal pressure was then applied and held constant to mimic the experimental setup. Degradation commenced only after full pressurisation of the vessel. Circumferential strain was exported and plotted against time during degradation for each pressure allowing for comparisons to be drawn with experimental data. The model was implemented using a user-defined material subroutine (UMAT) in the commercial finite element software, Abaqus 6.14 (Dassault Systèmes Simulia corporations, Vèlizy-Villacoublay, France). A numerical method to compute the tangent matrix was implemented (Miehe, 1996; Nolan et al., 2014; Sun et al., 2008).
A

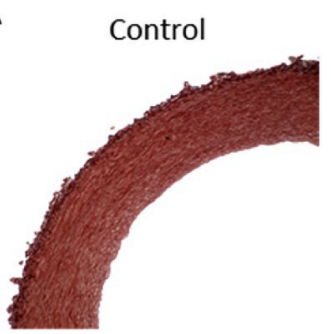

B $60 \mathrm{mmHg}, 8$ hours

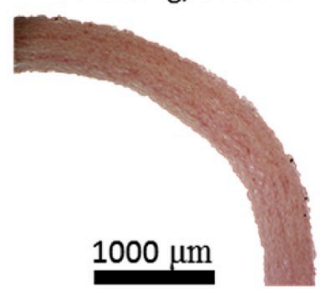

Fig. 8. Histological images of picrosirius red stained artery cross sections at $4 x$ magnification for a A) control vessel and B) a vessel subjected to $60 \mathrm{mmHg}$ in the presence of collagenase for $8 \mathrm{~h}$ showing complete collagen degradation (confirmed under polarised light by black image, not shown). Collagen shows as dark red. Despite complete collagen degradation, no significant vessel expansion is found in Fig. 7A for the samples under $60 \mathrm{mmHg}$ pressure. (For interpretation of the references to colour in this figure legend, the reader is referred to the Web version of this article.)

Table 1

Parameters used in the current model.

\begin{tabular}{llll}
\hline Model component & Parameter & Value & Source \\
\hline Vessel setup & $\varphi_{f}$ & 0.42 & Gaul et al. (2018) \\
& $\varphi_{m}$ & 0.58 & Gaul et al. (2018) \\
& $\lambda_{p}^{\min }$ (outer wall) & 1.01 & Calibrated \\
& $\lambda_{p}^{\max }$ (inner wall) & 1.19 & Calibrated \\
& $R_{i}(\mathrm{~mm})$ & 2.00 & Idealised \\
& $R_{o}(\mathrm{~mm})$ & 3.00 & Idealised \\
Material properties & $l(m m)$ & 0.5 & Idealised \\
& $\mathrm{E}(\mathrm{MPa})$ & 0.20 & Calibrated \\
& $\nu$ & 0.49 & Idealised \\
& $\kappa(\mathrm{MPa})$ & \multicolumn{1}{c}{$E$} & - \\
& $G(\mathrm{MPa})$ & $3(1-2 \nu)$ & - \\
& $k_{1}(\mathrm{kPa})$ & $2.1+\nu)$ & Calibrated \\
& $k_{2}$ & 7.56 & Calibrated \\
& $\left.\theta_{\text {collagen }}{ }^{\circ}\right)$ & 0 & Gaul et al. (2017) \\
& $\varepsilon_{t 1}^{D}$ & 0.08 & Gaul et al. (2018) \\
& $\varepsilon_{\mathrm{t} 2}^{D}$ & 0.23 & Gaul et al. (2018) \\
& $D_{l}\left(m s^{-1}\right)$ & -1.50 & Gaul et al. (2018) \\
& $D_{h}\left(m s^{-1}\right)$ & 0.75 & Gaul et al. (2018) \\
& $D_{c}\left(m s^{-1}\right)$ & 0.21 & Gaul et al. (2018) \\
& $\mathrm{R}$ & 0.0001 & Gaul et al. (2018) \\
\hline
\end{tabular}

A

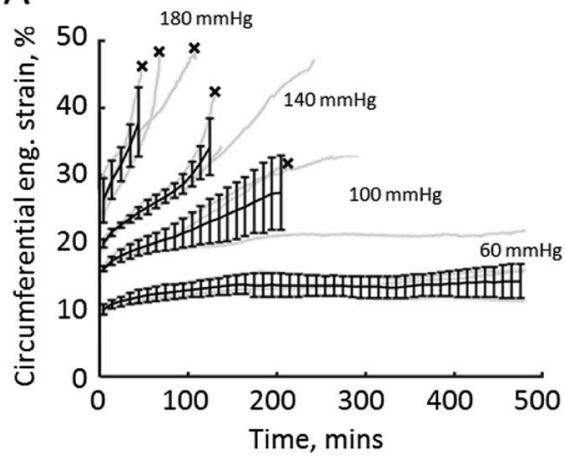

B

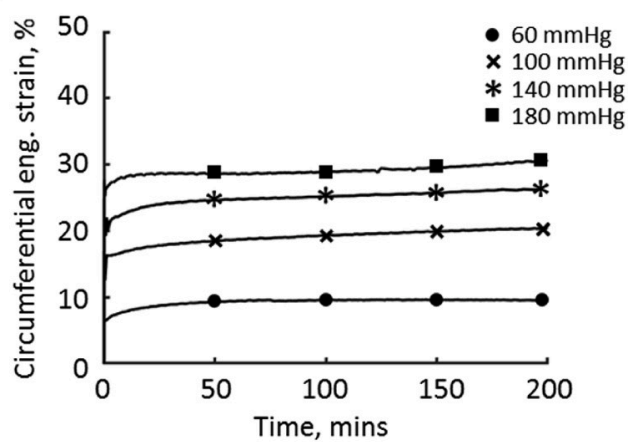

Fig. 7. Experimental pressure-inflation response over time of A) vessels in purified bacterial collagenase $(n=3)$ and B) control vessels in PBS $(n=1)$. Noticeable creep can be observed in the degradation case, particularly at high pressures. Control vessels show minimal expansion after the initial creep response within the first $20 \mathrm{~min}$. Individual vessels are plotted in grey while the mean response per pressure is shown in black alongside error bars of SD. Vessels which failed through rupture are marked with an x. Vessels which did not fail by rupture or last the 480-min test time failed due to the $16 \mathrm{ml}$ syringe emptying because of increased vessel permeability. 


\section{Results}

\subsection{Model calibration}

Experimental pressure-inflation experiments of the carotid vessels found a logarithmic type response with circumferential engineering strain plateauing at approximately $25 \%$ strain with increasing pressure (Fig. 6). A very close fit was achieved between our model and the mean experimental data with a root mean square error of $0.86 \%$ strain. As anticipated with biological tissue, however, considerable sample variability is observable with circumferential strain ranging from $19 \%$ to $33 \%$ at $180 \mathrm{mmHg}$.

\subsection{Experimental degradation curves}

Pressure inflation-degradation experiments showed significant circumferential vessel expansion with increasing pressure leading to vessel rupture (Fig. 7A). Vessels experiencing $180 \mathrm{mmHg}$ showed the highest rate of expansion while negligible expansion was observed in vessels experiencing $60 \mathrm{mmHg}$ despite complete collagen degradation (Fig. 8). Complete collagen degradation was confirmed by assessing polarised light images of picrosirius red stained histological tissue sections and noting the absence of any birefringence. Vessels which did not reach the $8 \mathrm{~h}$ end time of the experiment failed through either vessel rupture or loss of pressurisation fluid (collagenase) due to increasing vessel permeability during degradation. Vessels which failed through rupture are indicated symbolically in Fig. 7A.

Whilst a prescribed axial tethering was not imposed on the vessels during these experiments, the axial strain experienced by the vessels during pressurisation was measured using the DIC system and is reported in Supplementary data Fig. 1.3.

Significant reductions in vessel thickness $(0.919 \pm 0.026(0.112) \mathrm{mm}$ vs. $0.673 \pm 0.031(0.133) \mathrm{mm}, \mathrm{p}<0.0001)$ were also observed using a measuring microscope post degradation using a paired Wilcoxon nonparametric test for a non-normal frequency distribution (D'Agostino-Pearson normality test). Results are expressed as mean \pm SEM (SD).

Experimental pressure inflation experiments for undegraded control vessels (Fig. 7B) show no creep occurring with increasing time in comparison to collagenase treated vessels. Control vessels were found to reach approximately $90 \%$ of their final circumferential engineering strain within $20 \mathrm{~min}$ of pressurisation. No vessel failure was observed.

\subsection{Investigation of low pressure degradation}

Vessels experiencing $100 \mathrm{mmHg}$ prior to pressurising to $180 \mathrm{mmHg}$ exhibited significantly longer $(\mathrm{p}<0.05)$ failure times compared to those experiencing an initial $60 \mathrm{mmHg}$. This longer failure time suggests a strain-induced protection mechanism occurs at $100 \mathrm{mmHg}$ (Fig. 9). Failure time analysis provides additional insight, which is not visible in Fig. 7. One outlier as determined through a Grubbs outlier test (alpha =

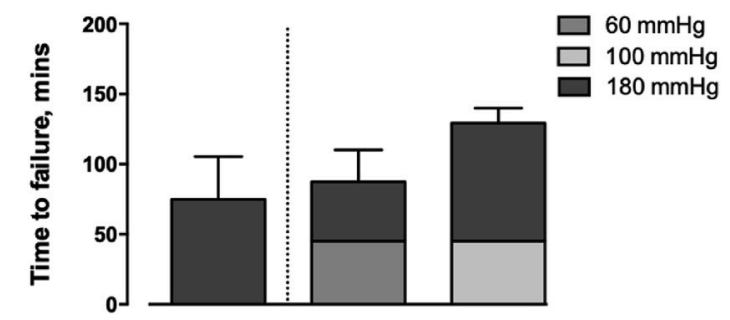

Fig. 9. Time to failure for specimen experiencing $180 \mathrm{mmHg}$ only (Fig. 7A) as well as those which were initially pressurised to $60 \mathrm{mmHg}$ or $100 \mathrm{mmHg}$ for 45 min before a high pressure of $180 \mathrm{mmHg}$ was applied until vessel failure ( $\mathrm{n}=$ 4). Vessels initially experiencing $100 \mathrm{mmHg}$ show increased time to failure suggesting slower initial degradation i.e. protection.
0.05) was removed from the $100 / 180 \mathrm{mmHg}$ data set, although this did not affect statistical significance. Complete data set including the outlier measurement is shown in Supplementary material.

\subsection{Modelling of collagen degradation in arteries}

A similar degradation expansion response was predicted by our model, with the highest rate of vessel expansion occurring at $180 \mathrm{mmHg}$ (Fig. 10). Our model also found minimal vessel expansion occurring at $60 \mathrm{mmHg}$ as observed experimentally, despite a high rate of collagen degradation. Differences can be seen between the rate of expansion predicted by our model and that observed experimentally, which may arise due to unaccounted factors such as the influence of diffusion of bacterial collagenase at different experimental pressures. At high pressure (140 $\mathrm{mmHg}$ and $180 \mathrm{mmHg}$ ), as collagen content reduces, strain exponentially increases, and the quasi-static simulation no longer converges upon a solution. Consequently, the simulation is stopped at $42 \%$ circumferential strain. The $100 \mathrm{mmHg}$ condition can be observed to level off at approximately $33 \%$ circumferential strain. At this point the collagen volume fraction has reduced to $0 \%$ and the intraluminal pressure is borne by the non-collagenous matrix alone. Plots of the collagen fibre volume fraction $\varphi_{f}$ and fibre stretch $\lambda_{f}$ are shown for $100 \mathrm{mmHg}$ in Fig. 11.

\section{Discussion}

Degradation of structurally significant collagen fibres is a critical process in healthy arterial remodelling; however, excessive degradation could potentially compromise vessel integrity leading to development of progressive, degenerative diseases such as aneurysm formation. The objective of this study was to investigate the degradation response of intact arterial vessels at physiologically relevant pressures using a combination of experimental and computational approaches.

In collagenase treated vessels, increasing vessel pressure resulted in an increased initial circumferential strain, an increased rate of vessel expansion and a reduced time to failure (Fig. 7). Ostensibly, these findings bear similarities to previous creep studies on collagenase treated bovine pericardium which found a reduced time to failure with increasing load (Ellsmere et al., 1999). Unlike our findings, a higher initial rate of expansion is observed in bovine pericardium experiencing low loads. These differences can be attributed to the greater mechanical contribution of non-collagenous matrix in arterial tissue which is the dominant load bearing constituent at low pressures (Roach and Burton, 1957), an effect which was found to be dominant in the degradation mechanics in our previous study (Gaul et al., 2018). This matrix response masks the underlying degradation response of collagen, especially at low pressures. Consequently, our low pressure condition (60

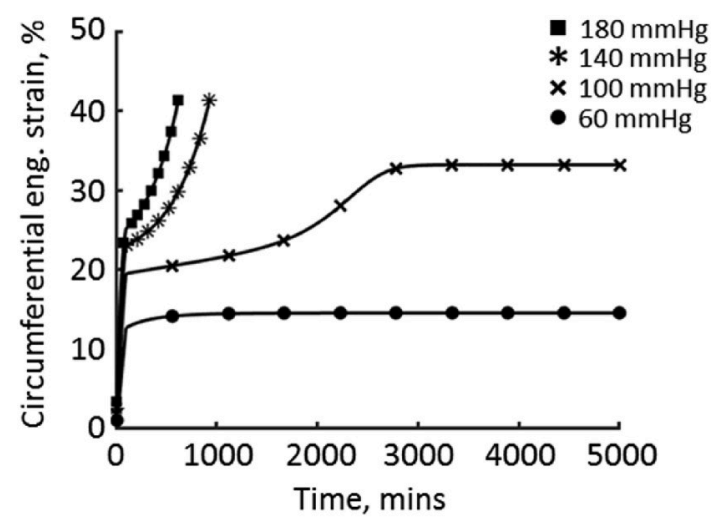

Fig. 10. Computational pressure-inflation response of degrading vessels at 60 , 100, 140 and $180 \mathrm{mmHg}$. Noticeable vessel expansion can be observed as vessels degrade, particularly at high pressures. 
A

$\underline{0 \mathrm{mmHg}}$

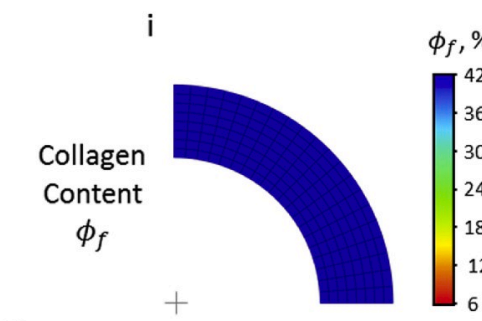

B

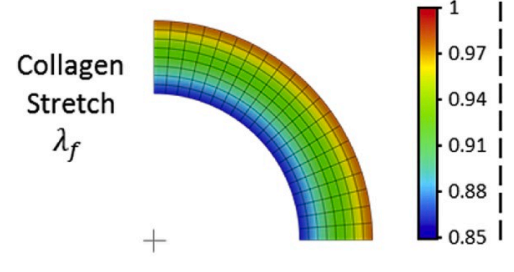

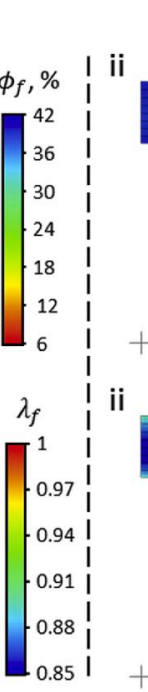

$\mathrm{t}=0 \mathrm{mins}$

$100 \mathrm{mmHg}$

iii
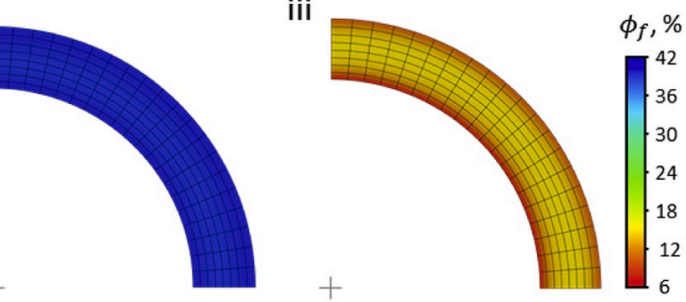

$\%$

42

30

18

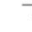

iii

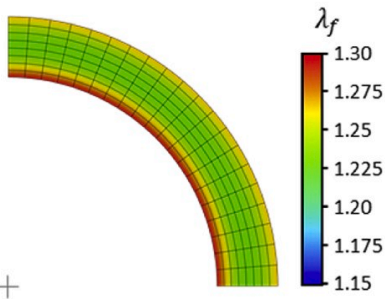

$\mathrm{t}=1500 \operatorname{mins}$

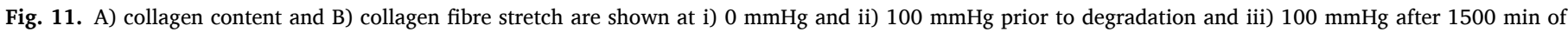

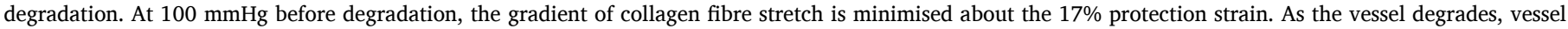
stretch and consequently fibre stretch increases leading to further degradation. Note change of legend for collagen stretch at $100 \mathrm{mmHg}$

$\mathrm{mmHg}$ ), which was assumed to have a high rate of collagen degradation (Gaul et al., 2018), exhibited minimal degradation induced expansion. Consequently, there was no tissue level failure. Nevertheless, histological analysis of these vessels confirmed complete collagen degradation (see Fig. 8). This suggests that non-collagenous matrix prevents further vessel expansion at low pressures even in the absence of collagen. This hypothesis is supported by Fig. 6, which shows a linear strain-pressure response up to $80 \mathrm{mmHg}$, suggesting that collagen doesn't contribute significantly up to this pressure.

The increased rate of degradation at low pressures was also demonstrated through the two-pressure failure tests in Fig. 9 where one group was held at $60 \mathrm{mmHg}$ and another at $100 \mathrm{mmHg}$ for $45 \mathrm{~min}$ before being pressurised to $180 \mathrm{mmHg}$. The shorter time to failure in the 60-180 mmHg group compared to the $100-180 \mathrm{mmHg}$ group suggests that a higher degradation rate occurred at $60 \mathrm{mmHg}$ when compared to $100 \mathrm{mmHg}$. Extending these findings to in vivo conditions suggests that, although degradation may be elevated in low pressure environments, tissue failure is unlikely unless high pressure and subsequent increased strain conditions develop. This response could help to explain the increased risk of adverse clinical cardiovascular events associated with hypertension (WHO, 2014).

Our complementary computational model, calibrated from experimental data independent of the full artery pressure-expansion results presented in this paper, predicted a qualitatively similar degradation response occurring at each pressure (Fig. 7). The model supported experimental observations that minimal vessel expansion occurs with collagen degradation at $60 \mathrm{mmHg}$ due to the dominant mechanical contribution of the non-collagenous matrix. A similar response is also observed in our $100 \mathrm{mmHg}$ model where strain plateaus as collagen is removed and pressure is borne by non-collagenous matrix alone. This response is partially observed experimentally, with the two $100 \mathrm{mmHg}$ tests found not to fail by rupture also displaying a plateauing at approximately $200 \mathrm{~min}$. We previously reported a similar noncollagenous matrix influence occurring in flat dogbone specimens of arterial tissue which masked an underlying V-shaped collagen degradation response (Gaul et al., 2018). Despite the same apparent mechanism being responsible for the current findings, degradation manifests itself differently during pressure dependent testing (increasing expansion rate with increasing pressure), which may lead one to incorrectly conclude that degradation linearly increases with pressure or strain. The model also supports the hypothesis that a degradation minimum exists at healthy physiological pressures $(100 \mathrm{mmHg})$, which may be the body's way of maintaining homeostasis or equilibrium in vivo. Consequently, abnormal blood pressure levels may lead to accelerated collagen degradation which could exceed collagen production. Interestingly, a number of studies on other biological tissues have also found a V-shaped degradation response occurring at the tissue level (Ghazanfari et al., 2016a; Yi et al., 2016). This observation suggests that for these tissues, i.e. pericardium and lung respectively, the non-collagenous matrix has a reduced mechanical contribution at low strains which does not mask the underlying collagen degradation response.

Although the same trend in degradation was found between our model and the experimental results, the rate at which degradation occurs was found to differ significantly. These differences are likely influenced by several factors. Firstly, although there is no significant creep observed in control vessels, there may be long-term pressuredependent creep mechanisms influencing the degradation results. The rate of collagenase diffusion through the artery wall also differs at each pressure condition, with greater diffusion occurring at higher pressures (Zareian et al., 2010). There is little or no pressure induced diffusion in the experiments from which some of the computational model parameters are derived (Gaul et al., 2018). The influence of diffusion of bacterial collagenase is also highlighted histologically when comparing the timeframes required to investigate degradation with and without pressure (see Supplementary material). As a result, the rate of degradation and subsequent vessel expansion identified computationally is much slower than that observed experimentally. Secondly, sample variability, which was noted in Fig. 6, is likely to influence the fibre strain, and consequently, the rate of collagen degradation. Additional failure modes other than fibre degradation such as fibre rupture are also likely to occur at increased pressures and may lead to further differences between experimental and computational results.

A number of computational models have been developed to investigate collagen remodelling in soft tissues adopting strain- and energybased approaches to reduce collagen volume fraction or collagen fibre radius. However, many of these models assume a strain-protection mechanism only in the prediction of tissue degradation ex vivo (Gyoneva et al., 2016; Hadi et al., 2012; Heck et al., 2015; Tonge et al., 2015). Similar degradation models have been employed to investigate valve 
retraction in tissue-engineered heart valves (Loerakker et al., 2016) and lamina cribosa thickening in glaucoma (Grytz et al., 2012) in vivo; however, to our knowledge, this is the first time that such a computational approach, informed by tailored experiments, has been adopted for investigating potential degenerative arterial diseases.

The proposed computational model may now provide insights into fatal degenerative arterial diseases such as aneurysm progression or arterial disease within complex vessel geometries and loading environments. Applying this model to arterial diseases such as atherosclerosis may help identify vessels at risk of plaque rupture due to excessive collagen degradation at sites of higher or low strain. Similarly, the current model may also aid in our understanding of the remodelling response caused by medical devices such as stents and prosthetic heart valves, which change the local mechanical environment of arterial collagen (Ghazanfari et al., 2016b).

A limitation of the current study is the use of bacterial collagenase rather than physiologically relevant MMPs and cysteine collagenases, which degrade collagen in vivo (Abdul-Hussien et al., 2007; Aikawa, 2004). Bacterial collagenases also commonly contain non-specific enzymes which can influence the experimental degradation response; however, this was mitigated through the use of purified bacterial collagenase (Gaul et al., 2018). Diffusion of the collagenase solution through the vessel wall is also likely to influence the rate of degradation observed (Zareian et al., 2010), with accelerated diffusion occurring at higher pressures. Unfortunately, diffusion and pressure are intrinsically linked in the current experimental setup, with pressure dictating the strain experienced in the vessel wall. Computationally, a diffusion rate could be incorporated to account for these differences, although the current predictions are suitably accurate even without accounting for diffusion. Furthermore, diffusion would only serve to increase the accuracy of our model in predicting our experimental data, given that diffusion is less physiologically relevant when one considers that in vivo collagenase production occurs in situ (Aikawa, 2004). Vessel variability is also likely to influence the degradation response based on factors such as vessel diameter and tissue thickness as well as collagen and elastin content. The current experimental setup is also designed to neglect axial tethering, in order to determine a clear understanding of how the degradation response differs in intact vessels and uniaxial dogbone specimens (Gaul et al., 2018). Interestingly, Ellsmere et al. found that cyclic loading, an environment experienced physiologically by arterial tissue, accelerated the degradation response of bovine pericardium. Future work will consider these more complex loading conditions and the axial stretch on the vessel which would likely have a significant influence on the collagen fibre strains.

The results of the current study have identified, for the first time, the strain-dependent degradation response of intact arterial vessels at physiologically relevant pressures. These findings have significantly expanded on previous work on flat dogbone arterial specimens, identifying a different tissue level response occurring in the native arterial state. Increased rates of vessel expansion were found to occur at high intraluminal pressures, along with an increased rate of collagen degradation at low vessel pressures. These findings highlight how arterial collagen strain may contribute to accelerated collagen degradation in diseases such as aneurysm progression in vivo and may also apply in other progressive degenerative vascular diseases, including the biological response to intravascular medical devices such as stents.

\section{Declaration of competing interest}

The authors declare that they have no known competing financial interests or personal relationships that could have appeared to influence the work reported in this paper.

\section{Acknowledgements}

This publication has emanated from research conducted with the financial support of the Irish Research Council (GOIPG/2014/515), Science Foundation Ireland under the Grant Number SFI/13/ERC/ B2775 and SFI/13/CDA/2145 and the European Research Council (ERC) under the European Union's Horizon 2020 research and innovation programme (grant agreement No. 637674)

\section{Appendix A. Supplementary data}

Supplementary data to this article can be found online at https://doi. org/10.1016/j.jmbbm.2020.103771.

\section{References}

Abdul-Hussien, H., Soekhoe, R.G.V., Weber, E., von der Thüsen, J.H., Kleemann, R., Mulder, A., van Bockel, J.H., Hanemaaijer, R., Lindeman, J.H.N., 2007. Collagen degradation in the abdominal aneurysm. Am. J. Pathol. 170, 809-817. https://doi. org/10.2353/ajpath.2007.060522.

Aikawa, M., 2004. Vascular biology of collagenases in vulnerable atherosclerotic plaques. Int. Congr. Ser. 1262, 67-70. https://doi.org/10.1016/j.ics.2003.12.056.

Bersi, M.R., Bellini, C., Humphrey, J.D., Avril, S., 2019. Local variations in material and structural properties characterize murine thoracic aortic aneurysm mechanics. Biomech. Model. Mechanobiol. 18 (1), 203-218. https://doi.org/10.1007/s10237018-1077-9.

Chang, S.-W., Buehler, M.J., 2014. Molecular biomechanics of collagen molecules. Mater. Today 17, 70-76. https://doi.org/10.1016/j.mattod.2014.01.019.

Chang, S.-W., Flynn, B.P., Ruberti, J.W., Buehler, M.J., 2012. Molecular mechanism of force induced stabilization of collagen against enzymatic breakdown. Biomaterials 33, 3852-3859. https://doi.org/10.1016/j.biomaterials.2012.02.001.

Daemen, M.J., Ferguson, M.S., Gijsen, F.J., Hippe, D.S., Kooi, M.E., Demarco, K., van der Wal, A.C., Yuan, C., Hatsukami, T.S., 2016. Carotid plaque fissure: an underestimated source of intraplaque hemorrhage. Atherosclerosis 254, 102-108. https://doi.org/10.1016/j.atherosclerosis.2016.09.069.

de Figueiredo Borges, L., Jaldin, R.G., Dias, R.R., Stolf, N.A.G., Michel, J.B., Gutierrez, P. S., 2008. Collagen is reduced and disrupted in human aneurysms and dissections of ascending aorta. Hum. Pathol. 39, 437-443. https://doi.org/10.1016/j. humpath.2007.08.003.

Driessen, N.J.B., Mol, A., Bouten, C.V.C., Baaijens, F.P.T., 2007. Modeling the mechanics of tissue-engineered human heart valve leaflets. J. Biomech. 40, 325-334. https:// doi.org/10.1016/j.jbiomech.2006.01.009.

Ellsmere, J.C., Khanna, R.A., Michael Lee, J., 1999. Mechanical loading of bovine pericardium accelerates enzymatic degradation. Biomaterials 20, 1143-1150. https://doi.org/10.1016/S0142-9612(99)00013-7.

Fischer, G.M., Llaurado, J.G., 1966. Collagen and elastin content in canine arteries selected from functionally different vascular beds. Circ. Res. 19, 394-399. https:// doi.org/10.1161/01.RES.19.2.394.

Gaul, R.T., Nolan, D.R., Lally, C., 2017. Collagen fibre characterisation in arterial tissue under load using SALS. J. Mech. Behav. Biomed. Mater. 75, 359-368. https://doi. org/10.1016/j.jmbbm.2017.07.036.

Gaul, R.T., Nolan, D.R., Ristori, T., Bouten, C.V.C., Loerakker, S., Lally, C., 2018. Strain mediated enzymatic degradation of arterial tissue: insights into the role of the noncollagenous tissue matrix and collagen crimp. Acta Biomater. 77, 301-310. https:// doi.org/10.1016/j.actbio.2018.06.037.

Ghazanfari, S., Driessen-Mol, A., Bouten, C.V.C., Baaijens, F.P.T., 2016a. Modulation of collagen fiber orientation by strain-controlled enzymatic degradation. Acta Biomater. 35, 118-126. https://doi.org/10.1016/j.actbio.2016.02.033.

Ghazanfari, S., Driessen-Mol, A., Hoerstrup, S.P., Baaijens, F.P.T., Bouten, C.V.C., 2016b. Collagen matrix remodeling in stented pulmonary arteries after transapical heart valve replacement. Cells Tissues Organs 201, 159-169. https://doi.org/10.1159/ 000442521.

Grytz, R., Sigal, I.A., Ruberti, J.W., Meschke, G., Crawford Downs, J., 2012. Lamina cribrosa thickening in early glaucoma predicted by a microstructure motivated growth and remodeling approach. Mech. Mater. 44, 99-109. https://doi.org/ 10.1016/j.mechmat.2011.07.004.

Gyoneva, L., Hovell, C.B., Pewowaruk, R.J., Dorfman, K.D., Segal, Y., Barocas, V.H., 2016. Cell-matrix interaction during strain-dependent remodelling of simulated collagen networks. Interface Focus 6. https://doi.org/10.1098/rsfs.2015.0069, 20150069.

Hadi, M.F., Sander, E.A., Ruberti, J.W., Barocas, V.H., 2012. Simulated remodeling of loaded collagen networks via strain-dependent enzymatic degradation and constantrate fiber growth. Mech. Mater. 44, 72-82. https://doi.org/10.1016/j. mechmat.2011.07.003.

Heck, T.A.M., Wilson, W., Foolen, J., Cilingir, A.C., Ito, K., van Donkelaar, C.C., 2015 A tissue adaptation model based on strain-dependent collagen degradation and contact-guided cell traction. J. Biomech. 48, 823-831. https://doi.org/10.1016/j. jbiomech.2014.12.023.

Holzapfel, G.A., Sommer, G., Auer, M., Regitnig, P., Ogden, R.W., 2007. Layer-specific $3 \mathrm{D}$ residual deformations of human aortas with non-atherosclerotic intimal thickening. Ann. Biomed. Eng. 35, 530-545. https://doi.org/10.1007/s10439-0069252-z.

Huang, C., Yannas, I.V., 1977. Mechanochemical studies of enzymatic degradation of insoluble collagen fibers. J. Biomed. Mater. Res. 11, 137-154. https://doi.org/ 10.1002/jbm.820110113. 
Junqueira, L.C.U., Bignolas, G., Brentani, R.R., 1979. Picrosirius staining plus polarization microscopy, a specific method for collagen detection in tissue sections. Histochem. J. 11, 447-455. https://doi.org/10.1007/BF01002772.

Krasny, W., Morin, C., Magoariec, H., Avril, S., 2017. A comprehensive study of layerspecific morphological changes in the microstructure of carotid arteries under uniaxial load. Acta Biomater. 57, 342-351. https://doi.org/10.1016/j. actbio.2017.04.033.

Loerakker, S., Obbink-Huizer, C., Baaijens, F.P.T., 2014. A physically motivated constitutive model for cell-mediated compaction and collagen remodeling in soft tissues. Biomech. Model. Mechanobiol. 13, 985-1001. https://doi.org/10.1007/ s10237-013-0549-1.

Loerakker, S., Ristori, T., Baaijens, F.P.T., 2016. A computational analysis of cellmediated compaction and collagen remodeling in tissue-engineered heart valves. J. Mech. Behav. Biomed. Mater. 58, 173-187. https://doi.org/10.1016/j. jmbbm.2015.10.001.

Lotz, J.C., Hadi, T., Bratton, C., Reiser, K.M., Hsieh, A.H., 2008. Anulus fibrosus tension inhibits degenerative structural changes in lamellar collagen. Eur. Spine J. 17, 1149-1159. https://doi.org/10.1007/s00586-008-0721-y.

Miehe, C., 1996. Numerical computation of algorithmic (consistent) tangent moduli in large-strain computational inelasticity. Comput. Methods Appl. Mech. Eng. 134, 223-240. https://doi.org/10.1016/0045-7825(96)01019-5.

Miles, C.A., Ghelashvili, M., 1999. Polymer-in-a-Box mechanism for the thermal stabilization of collagen molecules in fibers. Biophys. J. 76, 3243-3252. https://doi. org/10.1016/S0006-3495(99)77476-X.

Müller-Schweinitzer, E., 2009. Cryopreservation of vascular tissues. Organogenesis 5, 97-104. https://doi.org/10.4161/org.5.3.9495.

Nabeshima, Y., Grood, E.S., Sakurai, A., Herman, J.H., 1996. Uniaxial tension inhibits tendon collagen degradation by collagenase in vitro. J. Orthop. Res. 14, 123-130. https://doi.org/10.1002/jor.1100140120.

Nolan, D.R., Gower, a.L., Destrade, M., Ogden, R.W., McGarry, J.P., 2014. A robust anisotropic hyperelastic formulation for the modelling of soft tissue. J. Mech. Behav. Biomed. Mater. 39, 48-60. https://doi.org/10.1016/j.jmbbm.2014.06.016.

O'Connor, C.A., Nolan, D.R., McEvoy, E., McGarry, J.P., 2017. A three part hyperelastic law for anisotropic aortic tissue: model development and experimental validation. In: Summer Biomechanics, Bioengineering and Biotransport Conference. Arizona.

Pegg, D.E., Wusteman, M.C., Boylan, S., 1997. Fractures in cryopreserved elastic arteries. Cryobiology 34, 183-192. https://doi.org/10.1006/cryo.1996.1997.

Roach, M.R., Burton, a C., 1957. The reason for the shape of the distensibility curves of arteries. Can. J. Biochem. Physiol. 35, 681-690. https://doi.org/10.1139/057-080.

Robitaille, M.C., Zareian, R., Dimarzio, C. a, Wan, K.-T., Ruberti, J.W., 2011. Small-angle light scattering to detect strain-directed collagen degradation in native tissue. Interface Focus 1, 767-776. https://doi.org/10.1098/rsfs.2011.0039.

Ruberti, J.W., Hallab, N.J., 2005. Strain-controlled enzymatic cleavage of collagen in loaded matrix. Biochem. Biophys. Res. Commun. 336, 483-489. https://doi.org/ 10.1016/j.bbrc.2005.08.128.
Sáez, P., García, A., Peña, E., Gasser, T.C., Martínez, M.A., 2016. Microstructural quantification of collagen fiber orientations and its integration in constitutive modeling of the porcine carotid artery. Acta Biomater. 33, 183-193. https://doi.org/ 10.1016/j.actbio.2016.01.030.

Schneider, C. a, Rasband, W.S., Eliceiri, K.W., 2012. NIH Image to ImageJ: 25 years of image analysis. Nat. Methods 9, 671-675. https://doi.org/10.1038/nmeth.2089.

Schriefl, A.J., Zeindlinger, G., Pierce, D.M., Regitnig, P., Holzapfel, G.A., 2012. Determination of the layer-specific distributed collagen fibre orientations in human thoracic and abdominal aortas and common iliac arteries. J. R. Soc. Interface 9 1275-1286. https://doi.org/10.1098/rsif.2011.0727.

Shahid, S.S., Gaul, R.T., Kerskens, C.M., Flamini, V., Lally, C., 2017. Quantifying the ultrastructure of carotid artery using high-resolution micro-diffusion tensor imaging - comparison of intact vs. open cut tissue. Phys. Med. Biol. 62, 8850-8868. https:// doi.org/10.1088/1361-6560/aa9159.

Sun, W., Chaikof, E.L., Levenston, M.E., 2008. Numerical approximation of tangent moduli for finite element implementations of nonlinear hyperelastic material models. J. Biomech. Eng. 130, 061003 https://doi.org/10.1115/1.2979872.

Thompson, R.W., Geraghty, P.J., Lee, J.K., 2002. Abdominal aortic aneurysms: basic mechanisms and clinical implications. Curr. Probl. Surg. 39, 110-230. https://doi. org/10.1067/msg.2002.121421.

Tonge, T.K., Ruberti, J.W., Nguyen, T.D., 2015. Micromechanical modeling study of mechanical inhibition of enzymatic degradation of collagen tissues. Biophys. J. 109, 2689-2700. https://doi.org/10.1016/j.bpj.2015.10.051.

Trabelsi, O., Dumas, V., Breysse, E., Laroche, N., Avril, S., 2019. In vitro histomechanical effects of enzymatic degradation in carotid arteries during inflation tests with pulsatile loading. J. Mech. Behav. Biochem.Mater 103, 103550.

Tsamis, A., Krawiec, J.T., Vorp, D. a, 2013. Elastin and collagen fibre microstructure of the human aorta in ageing and disease: a review. J. R. Soc. Interface 10. https://doi. org/10.1098/rsif.2012.1004, 20121004.

WHO, 2014. Global Status Report on Noncommunicable Diseases 2014.

Willett, T.L., Labow, R.S., Lee, J.M., 2008. Mechanical overload decreases the thermal stability of collagen in an in vitro tensile overload tendon model. J. Orthop. Res. 26, 1605-1610. https://doi.org/10.1002/jor.20672.

Wyatt, K.E.-K., Bourne, J.W., Torzilli, P. a, 2009. Deformation-dependent enzyme mechanokinetic cleavage of type I collagen. J. Biomech. Eng. 131, 051004 https:// doi.org/10.1115/1.3078177.

Yi, E., Sato, S., Takahashi, A., Parameswaran, H., Blute, T.A., Bartolák-Suki, E., Suki, B., 2016. Mechanical forces accelerate collagen digestion by bacterial collagenase in lung tissue strips. Front. Physiol. 7, 1-12. https://doi.org/10.3389/ fphys.2016.00287.

Zareian, R., Church, K.P., Saeidi, N., Flynn, B.P., Beale, J.W., Ruberti, J.W., 2010. Probing collagen/enzyme mechanochemistry in native tissue with dynamic, enzymeinduced creep. Langmuir 26, 9917-9926. https://doi.org/10.1021/la100384e. 